\title{
O (re)nascimento de um corpo professoral: os estatutos do magistério público do Estado de Santa Catarina de 1960 e 1975
}

\author{
Ione Ribeiro Valle* \\ Danielly Samara Besen ${ }^{* *}$ \\ Silvana Rodrigues de Souza Sato***
}

\section{Resumo}

O presente artigo analisa uma das dimensões do processo histórico de democratização da educação no Estado de Santa Catarina, a saber: os estatutos do magistério público dos anos de 1960 e 1975, que regulamentaram a carreira do magistério, contribuindo, assim, para uma (re)definição da identidade dos professores e a consolidação da profissão docente. Dentre muitos aspectos que compõem a identidade profissional, destacam-se os de ordem moral, considerando-se três categorias: os requisitos para ingresso na carreira, as regras de permanência no magistério e as sanções disciplinares. Os documentos, por intermédio da instituição de competências e condutas que deveriam ser seguidas por todos, estabelecem uma ordem moral e inauguram uma ordem professoral. Constata-se a continuidade de grande parte das prerrogativas legais que orientaram a constituição do corpo docente no início dos anos 1960 e o estabelecimento de novas regras para o exercício do magistério nos anos 1975. Verifica-se também que os dois dispositivos apresentam um caráter normativo fortemente fundado em regras morais, o que levou a buscar os escritos de Émile Durkheim (1858-1917) relacionados ao elemento disciplinar da moralidade.

Palavras-chave: Estatutos do magistério. Identidade profissional. Ordem moral.

\footnotetext{
* ** Pós-doutora pela École des Hautes Études en Sciences Sociales, Paris. Doutora em Ciências da Educação pela Université René Descartes, Paris V, França. Professora do Centro de Ciências da Educação e Coordenadora do Programa de Pós-Graduação em Educação na Universidade Federal de Santa Catarina (UFSC).

** Mestra em Educação pela Universidade Federal de Santa Catarina (UFSC).

${ }^{* * *}$ Mestra e Doutoranda em Educação pela Universidade Federal de Santa Catarina (UFSC).
} 
Neste $\operatorname{artigo~}^{1}$ buscamos levantar e analisar elementos que permitem compreender o processo histórico de democratização da educação em Santa Catarina, tendo como referência algumas de suas múltiplas dimensões. Dedicamo-nos, para tanto, ao estudo de dispositivos legais que regulamentaram a carreira docente no Estado catarinense e que contribuíram para (re)definir a identidade do professor. Consideramos que a análise dessas prerrogativas, que, neste trabalho, abarca os estatutos do magistério público do Estado de Santa Catarina de 1960 e 1975 (SANTA CATARINA, 1960, 1976), aproxima-nos de aspectos mais gerais das políticas para a educação, traduzidas nas reformas educacionais ${ }^{2}$, na constituição das redes de ensino, mas também em ações e metas voltadas à configuração de um corpo professoral, particularmente no que concerne à sua formação, profissionalização e identidade profissional.

Nossa intenção ao examinar essas duas importantes peças regulamentares foi essencialmente situar alguns elementos de continuidade e/ou descontinuidade dispersos nas transformações morfológicas, de base legal, às quais foi submetido o corpo docente catarinense. Partimos do pressuposto que esses estatutos estão na base das ações empreendidas pelos regimes políticos daquele momento histórico, constituindo-se, inclusive, em chave para a compreensão das políticas educacionais postas em prática ulteriormente. Nosso intuito é, portanto, acrescentar mais uma peça explicativa no mosaico que caracteriza a educação catarinense e brasileira, partindo do pressuposto que essas transformações se inscrevem num quadro mais amplo de configuração do campo educacional. Vale assinalar, também, que esses dois estatutos foram aprovados em contextos polarizados da política educacional brasileira: o primeiro (SANTA CATARINA, 1960) precede o regime autoritário estando voltado a uma política mais geral de democratização da sociedade brasileira; e o segundo (SANTA CATARINA, 1976) inscreve-se no quadro das medidas autoritárias do regime ditatorial.

A composição de um corpo docente unificado sempre foi vislumbrada pelas esferas administrativas responsáveis pelos sistemas de ensino, especialmente aquelas vinculadas ao regime ditatorial pós-1964. No Estado catarinense essa preocupação se intensificou quando as iniciativas governamentais passaram a investir, de maneira mais efetiva, na formação do magistério e na sua profissionalização (VALLE, 2003). Não se tratava evidentemente de promover uma unificação plena em termos administrativos ou da estruturação de sua carreira profissional, mas de engendrar certa "unidade de espírito" no plano essencialmente ideológico, capaz de orientar práticas suficientemente homogêneas e que, gradativamente, foram sendo submetidas a um controle mais rigoroso. Dessa forma, os programas que promoveram a formação do magistério não se limitaram à transmissão de saberes 
disciplinares e/ou pedagógicos, mas voltaram-se também ao desenvolvimento de competências de ordem organizacional, profissional, política e meritocrática. Associadas às particularidades da carreira docente na sua relação com as finalidades educacionais estabelecidas pelas diretrizes dos diferentes governos, essas competências foram sendo delineadas pela legislação destinada ao magistério e incorporadas pelos programas de formação docente.

É com esse olhar que nos dedicamos à análise dos Estatutos do Magistério Público Estadual (SANTA CATARINA, 1960, 1976), considerando-os como instrumentos de composição e de constituição de uma carreira profissional, uma vez que prescrevem normativas tanto aos que já pertencem quanto aos que almejam nele ingressar. Esses estatutos visam fortalecer os vínculos entre os indivíduos que fazem parte do magistério ao estabelecerem normas a serem rigorosamente seguidas. Eles auxiliam na edificação de um corpo profissional, legitimando, assim, uma identidade comum à carreira. Dentre os muitos aspectos que compõem esta identidade profissional, destacamos aqueles de ordem moral, considerando três categorias de análise: os requisitos de ingresso nos cargos, as regras de permanência na carreira e as sanções disciplinares. Para tecer este estudo, inspiramo-nos em duas obras de Émile Durkheim (1858-1917): Educação e sociologia e $A$ educação moral ${ }^{3}$, por entendermos que a reflexão teórica ali desenvolvida permite compreender o caráter normativo dos dispositivos educacionais, postos em vigência pelo Estado catarinense naquele momento histórico, os quais se mostraram fortemente fundados em regras morais.

\section{A teoria sociológica de Émile Durkheim e o pensamento educacional brasileiro}

É por estarmos convencidas de que a abordagem sociológica de Émile Durkheim exerceu grande influência sobre o pensamento educacional brasileiro ao longo do século XX, com consequências importantes sobre a constituição dos nossos sistemas de ensino, que retomamos sua reflexão sobre o caráter moral da educação escolar. Partimos, portanto, do pressuposto que esta perspectiva teórica permite compreender a força normativa das instâncias de administração brasileira e catarinense, particularmente em relação à determinação de regras morais para o exercício do magistério.

A obra A educação moral reúne lições ministradas por Émile Durkheim (2008) na universidade francesa no início do século XX, nas quais o autor problematizava a educação moral e o lugar que esta 
nova moralidade (uma moral laica) deveria ocupar na formação das novas gerações. Nessas aulas, ele dá continuidade à reflexão sobre a função social da escola, que foi objeto da obra Educação $e$ sociologia (DURKHEIM, 1978), argumenta em favor de uma educação moral laica e procura evidenciar sua importância na consolidação de uma sociedade em processo acelerado de transformação e de modernização, mas que carecia de elementos de coesão social.

Nas sociedades consideradas por Durkheim como primitivas, onde imperava a solidariedade mecânica ${ }^{4}$, as noções religiosas condicionavam o conteúdo do pensamento humano ao de suas divindades. Nessas sociedades a moral não poderia ser outra senão a moral religiosa que acabou predominando nas escolas. Para substituir a moral religiosa por uma laica era preciso, inicialmente, descobrir a força moral presente no símbolo religioso para, posteriormente, tratá-lo de maneira racional. Durkheim (2008, p. 24) reconhecia que esses dois sistemas de pensamento - fé e razão estiveram unidos de forma intensa ao longo da história, o que tornava impossível uma separação abrupta: "Essa aliança não deve surpreender-nos, se levarmos em consideração que os deveres da religião e aqueles da moral têm em comum o fato de ambos serem deveres, isto é, são práticas moralmente obrigatórias".

O desafio que se impôs aos Estados modernos foi, portanto, o de laicizar o ensino, o que significava a oferta de uma educação pública, gratuita, laica e obrigatória para todos e, consequentemente, um processo de monopolização do Estado em matéria de educação escolar. Esta deveria orientar-se segundo os pressupostos da racionalidade, pois as explicações morais de cunho religioso não mais se adequavam às necessidades da sociedade - urbana e industrial - que emergia. Assim sendo, a educação moral laica pautar-se-ia exclusivamente em ideias, sentimentos e práticas racionais, colocando-se a serviço da transmissão de saberes científicos. Ela seria responsável, desse modo, pela promoção da solidariedade orgânica ${ }^{5}$, requerida pelos modernos Estados-nação.

Para concretizar a laicização moral, assinalava Durkheim (2008, p. 27), não basta “[...] tomar cuidado para que o processo de racionalização moral não perca nenhum de seus elementos constitutivos, mas, ainda, é preciso que ela possa ser enriquecida com novos elementos". No seu entendimento, o conteúdo dos deveres seria alterado no decorrer dessas mudanças, transformando as bases sobre as quais os preceitos morais de cunho religioso permaneciam apoiados. Essa nova configuração resultaria numa forma de organização social racional e implicaria outra relação de obediência: não mais entre deuses e homens, mas entre os próprios homens; não mais fundada na fé, mas orientada pela razão. 
Mas como operacionalizar uma educação moral laica? Como sabemos, a sociologia de Émile Durkheim não se limitou ao aspecto analítico. Preocupado com a coesão social e com o estabelecimento da ordem, o que segundo ele somente seria possível por meio da diferenciação social $^{6}$, sua perspectiva apresenta um caráter fortemente prescritivo. Ele acreditava que a moral laica poderia ser operada por meio de três elementos, a saber: o espírito de disciplina, a adesão aos grupos sociais e a autonomia da vontade. A definição dos fins da educação e dos objetivos das práticas escolares deveria resultar da articulação desses três elementos. Segundo o autor, a consolidação de uma moral laica deveria levar em conta o conjunto de regras que condicionam o comportamento dos indivíduos e que foram elaboradas previamente visando prepará-lo para o momento da ação. Tratava-se, assim, de prescrições genéricas, com caráter imperativo, competindo aos indivíduos particularizá-las ao agir: “[...] não existe profissão que não tenha regras a serem observadas. Todas as classes profissionais têm suas técnicas, ou seja, o código de princípios que consagrou seus procedimentos, que consolidou a profissão" (DURKHEIM, 2007, p. 64).

Foi essencialmente a partir desses três elementos que fundamentamos nossa análise dos estatutos do magistério público estadual de Santa Catarina de 1960 e 1975. Nosso interesse se voltou essencialmente, como vimos, à configuração de um corpo profissional. Nesse sentido, os estatutos do magistério estadual figuram como um importante instrumento de consolidação da profissão docente, pois, ao fixar critérios de entrada e permanência no magistério assim como competências profissionais, eles estabelecem condutas que devem ser observadas e seguidas, instituindo uma determinada ordem moral e inaugurando uma ordem a professar.

\section{A configuração do corpo professoral catarinense}

Para identificar elementos de uma moralidade laica nos dispositivos de formatação do corpo professoral, procuramos situar, ainda que de maneira genérica, o contexto educacional no qual se inscrevem os estatutos do magistério público do Estado de Santa Catarina de 1960 e 1975, dada a singularidade histórica destes períodos: passagem de um regime democrático a um regime ditatorial cuja autoridade vai sendo reafirmada e reforçada por meio da aplicação de dispositivos legais. Partimos do pressuposto, tendo como referência vários estudos desenvolvidos no campo da sociologia e da história da educação ${ }^{7}$, que a escolarização da população brasileira é bastante recente, e que sua 
progressão ao longo do século XX se dá de forma diversificada em termos geográficos, e de forma profundamente desigual em termos de origem social, econômica, cultural. Como mostram Valle e Ruschel (2009, p. 199), ao examinarem a legislação educacional brasileira e catarinense desde os anos de 1930, embora o discurso meritocrático tenha dado o tom às políticas para a educação no período entre ditaduras (1945-1964), “os índices de escolarização não corresponderam à amplitude dos propósitos oficiais e não responderam às demandas sociais". Ao segregar os alunos segundo suas origens, a escola reproduziu os destinos sociais e os legitimou fazendo apelo às diferenças individuais de performance (dom, talento, esforço, aproveitamento, capacidade, eficiência, inteligência, vocação).

Uma expansão importante das oportunidades escolares, sobretudo nas regiões urbanas, vai ocorrer a partir de meados da década de 1960, quando o Estado brasileiro, e catarinense, atribui de maneira mais incisiva à escola um papel central na modernização e promoção do desenvolvimento industrial por meio da preparação de "capital humano", , aproximando expectativas e aspirações, nem sempre equivalentes, do governo e da sociedade civil em termos educacionais. No entanto, apesar de promover uma ampliação significativa das oportunidades escolares, essas intenções não levaram à democratização da educação. Como mostram Valle e Ruschel (2009, p. 199), “a expansão se efetivou através de diferentes sistemas (público e privado) e redes de ensino (federal, estadual e municipal), de diferentes turnos de funcionamento (matutino, vespertino, noturno), de diferentes níveis de formação (fundamental, médio, superior), de distintas habilitações profissionais", mantendo assim a segregação histórica da educação brasileira segundo a origem dos alunos.

Efetivamente, os pilares de uma política educacional para o país começam a ser edificados em 1961 pela Lei de Diretrizes e Bases da Educação Nacional (Lei n ${ }^{\circ} 4.024$ ), embora o projeto de sistema nacional de educação tenha sido concebido desde os anos de 1920 pelos Pioneiros da Educação Nova e preconizado pela Constituição Federal de 1934. Mas a expectativa de expansão das oportunidades escolares se confrontou a todo o momento com a ausência de pessoal habilitado, seja na criação de uma escola ou de um novo nível de ensino. Isso exigiu que o Estado empreendesse múltiplas ações no que concerne à instauração das redes de ensino e das instâncias de administração educacional (ministério, secretarias e conselhos de educação). Nessa conjuntura, o corpo professoral parece ter sido o maior obstáculo à constituição dos sistemas de ensino, implicando a admissão de novos docentes, a formação daqueles que já atuavam em salas de aula e o estabelecimento de uma carreira profissional. A necessidade de professores, mas, sobretudo, de professores habilitados, tornou-se, portanto, o “calcanhar-de-aquiles” da política de democratização da educação das décadas de 1960 e 1970. 
Para assegurar as mudanças almejadas, inspiradas em princípios e ideais ligados à democratização da educação, o Estado catarinense procurou oferecer a prova de estar qualificado para conduzir o projeto de escolarização de sua população. Para tanto, empenhou-se em duas frentes essenciais: primeiramente, na definição de políticas para a educação nacional, o que ocorreu por meio do engajamento de autoridades educacionais de Santa Catarina em iniciativas do governo federal (VALLE, 2006); em segundo lugar, nas ações voltadas à consolidação dos seus sistemas de ensino (estadual e municipais) e, sobretudo, à conformação de um corpo professoral, o que se efetivou por meio da introdução de dispositivos reguladores, dentre eles os estatutos do magistério público estadual.

Visando à composição de uma carreira docente, esses estatutos prescreveram normas tanto para aqueles que já atuavam no ensino quanto para aqueles que pretendiam nele se inserir. Ao objetivar a edificação de um corpo professoral e de uma identidade profissional à luz das prerrogativas oficiais, eles fortaleceram os vínculos entre o pessoal da educação, fomentaram um sentimento de pertencimento ao corpo professoral por meio da promessa de um novo status para o magistério, em comum acordo com as mudanças preconizadas pelo novo regime.

\section{Os estatutos do magistério público catarinense: a prescrição de uma moralidade laica?}

Partimos do pressuposto que os estatutos do magistério público do Estado de Santa Catarina de 1960 e 1975 figuraram como importantes dispositivos de consolidação do corpo professoral, pois, ao definirem uma carreira para o magistério, instituíram elementos morais que delineiam uma identidade profissional. Além de fixar critérios para o ingresso no corpo docente e definir competências, eles estabeleceram condutas que devem ser seguidas pelos professores, instituindo consequentemente uma determinada ordem moral a ser professada. Ao estabelecer requisitos para o ingresso nos cargos, regras para a permanência na carreira e sanções disciplinares, esses estatutos viabilizaram o ideário político dos governos do Estado de Santa Catarina e põem em prática suas prerrogativas administrativas, em nome da proteção de princípios universais a serem zelados em prol do bem comum. Vale lembrar que, como mostra Durkheim (1978, p. 49):

[...] há na base de nossa civilização certo número de princípios que, implícita ou explicitamente, são comuns a todos, ou pelo menos que bem poucos ousam negar em 
sã consciência: o respeito da razão da ciência, das ideias e sentimentos em que se baseia a moral democrática. É função do Estado proteger esses princípios essenciais.

Essas normas previstas e fixadas pelos estatutos conferiram, portanto, legitimidade às políticas educacionais do Estado catarinense e definem parâmetros para uma identidade profissional do seu corpo docente. O documento de 1975 se mostra mais minucioso no que concerne à configuração do corpo docente, determinando que o mesmo seja constituído de professores e especialistas em assuntos educacionais com habilitações específicas para o exercício dessas funções (SANTA CATARINA, 1976). O magistério - de acordo com esse dispositivo legal - exige não apenas conhecimentos profundos e competências próprias à prática docente, adquiridos e desenvolvidos por meio de programas de formação inicial e contínua, mas também responsabilidades pessoais e coletivas para com a educação e o bem-estar dos alunos e da comunidade. Nesse sentido, é possível observar como as prerrogativas legais instituem referências de conduta moral para composição do magistério, seja em relação ao ingresso, à permanência nos cargos, aos direitos e deveres, às responsabilidades e às ações disciplinares a que estariam sujeitos os profissionais da educação.

\section{$O$ ingresso na carreira}

O Estatuto do Magistério Público Estadual de 1960 regulamenta os direitos, deveres e ações disciplinares para os membros do magistério (SANTA CATARINA, 1960). Esse texto legislativo mantém o ingresso mediante concurso, sendo que a boa conduta pública e privada são condições essenciais para nele permanecer. Fica estabelecido que os concursos poderiam ser de provas e títulos ou apenas de títulos. Para inscrever-se era necessária uma formação inicial comprovada pela posse de um título de conclusão de curso em "escolas oficiais" ou em escolas particulares reconhecidas pelo Estado ${ }^{9}$. Realizadas as provas era fornecido um certificado de habilitação aos aprovados. No entanto, essa norma legal poderia ser flexibilizada, pois havia uma cláusula que possibilitava o preenchimento dos cargos por professores não concursados. Evidentemente esta flexibilização dizia respeito à insuficiência de candidatos inscritos/aprovados face às necessidades manifestadas pelos sistemas de ensino do Estado. Nesse caso, poderiam ser admitidos professores em caráter interino, ou seja, seria outorgada a inscrição, em caráter "ex-officio", de proponentes sem a habilitação requerida no próximo concurso realizado. 
O documento de 1975 estabeleceu novas normas para os integrantes do magistério de $1^{\circ}$ e $2^{\circ}$ graus (SANTA CATARINA, 1976), seguindo as orientações do Plano Estadual de Educação de 1969/1980, que determinou a reformulação do Estatuto do Magistério Público Estadual de 1960, a fim de que fossem explicitados os direitos e deveres dos docentes e redefinidos os requisitos de ingresso na carreira. Vale lembrar que este estatuto se inscreve numa nova conjuntura política, marcada por medidas autoritárias, adotadas por um Estado ditatorial. Tais medidas implicaram a burocratização da Secretaria e do Conselho Estaduais de Educação (VALLE, 1996) e a profissionalização do corpo docente (VALLE, 2003). Para integrar o quadro do magistério passou a ser indispensável comprovar uma habilitação específica, obtida em cursos de formação profissional. A primeira ação a ser realizada por parte de um pretendente a um cargo no magistério público era a aprovação prévia em concurso público de provas ou de provas e títulos.

Além do quesito formação, outras condições para o ingresso foram estabelecidas: o Estatuto de $1960^{10}$ priorizava aspectos gerais relativos à adesão ao corpo profissional, de caráter individual, como: ser brasileiro, gozar de boa saúde, ter idade mínima de 18 anos para atuar no magistério primário e de 21 anos para o exercício docente no secundário, sendo a idade de 45 anos o limite máximo para ambos os cargos; de caráter político-administrativo, como estar no gozo dos direitos políticos, ter boa conduta pública e privada (SANTA CATARINA, 1960). Esses quesitos são mantidos no texto de 1975 sendo acrescida a apresentação de declaração comprobatória dos cargos anteriormente exercidos (SANTA CATARINA, 1976).

O elemento disciplinar da moralidade durkheimiana parece evidenciar-se em ambos os textos estatutários, pois cada candidato ao concurso para o ingresso deveria responder a todas as exigências legais para fazer parte do corpo docente estadual. Nota-se, assim, a presença marcante desse elemento que aparece como uma autoridade formal, convergente com as características dos estados modernos, cujo objetivo é regular a conduta individual esperada para o exercício de uma atividade funcional do interesse do bem comum. As prerrogativas dos estatutos abrangem, portanto, dimensões individuais e coletivas do candidato, previamente atestadas, ao determinar como requisito, por exemplo, a comprovação de uma "boa conduta pública e privada".

Segundo Durkheim (2008), o espírito de disciplina é fundamental à integração e regulação da vida social. O sentimento de pertencimento ao corpo profissional se concretiza tão somente após cada novo membro haver incorporado as expectativas do grupo, de maneira que elas passam a fazer parte de sua personalidade e definem sua identidade. Segundo o autor, é preciso que o indivíduo seja constituído 
de maneira a sentir a superioridade das forças morais, pois sempre que agimos moralmente produzimos uma violência contra nossas vontades, ao deixarmos de realizar ações centradas apenas nas nossas aspirações individuais. Essa seria a condição central para a saúde moral da sociedade e, em particular, do campo educacional, pois agir moralmente implica se mostrar conforme a consciência coletiva: “porque os homens vivem em conjunto, e não isolados, as consciências morais agem umas sobre as outras, e, em virtude das relações que surgem assim, são produzidos ideias e sentimentos que jamais poderiam ser produzidos pelas consciências isoladas" (DURKHEIM, 2008, p. 74).

Enfim, o espírito de disciplina é fundamental à adesão do indivíduo num determinado grupo social ou profissional, pois ao aderi-lo e a ele se amoldar o mesmo passa a refletir nas suas ações a consciência coletiva. Suas atitudes dentro do grupo devem visar sua manutenção e coesão e, fora dele, devem caminhar no sentido de transmitir uma imagem adequada do conjunto que ele representa. É esse espírito que os estatutos procuram promover. Embora os candidatos ao ingressar na carreira docente apresentassem as principais características requeridas pelo conjunto do magistério, seria após sua inserção no corpo profissional que passariam a com ele se identificar e, sobretudo, a reafirmar os interesses dos seus pares, deixando de proceder unicamente a partir de desejos pessoais.

\section{A permanência no magistério, fruto da relação entre direitos e deveres}

As normas morais exigidas dos membros do magistério público estadual para permanência no corpo docente são descritas detalhadamente nos documentos analisados na seção referente aos deveres e responsabilidades ${ }^{11}$. Esses documentos reafirmam a lógica preconizada por Durkheim, especificamente no que concerne à instituição de uma moral laica. Destacam-se nessas seções regras de diferentes dimensões que se interconectam, a saber: as comportamentais, abrangendo o respeito à lei e às ordens superiores; a manutenção do espírito de cooperação e de solidariedade com os colegas, o reconhecimento do estatuto profissional e da hierarquia, o amparo à família; aquelas afetas à rotina profissional, contemplando o comparecimento ao estabelecimento de ensino nas horas do trabalho ordinário e extraordinário para a execução dos serviços determinados pelas autoridades, o empenho na educação integral dos alunos incutindo-lhes o espírito de solidariedade humana, de justiça e de cooperação, o uso de processos de ensino vinculados aos conceitos de educação e de aprendizagem pelo governo do Estado, a sugestão de providências que visem à melhoria do sistema de ensino, a frequência nos cursos de aperfeiçoamento, a apresentação de relatórios das atividades, a organização de 
leis e ordens de serviço fornecidas pelo Estado; e as que tangem a hierarquia, referindo-se ao respeito às autoridades constituídas, o amor à Pátria, ao desempenho com zelo dos trabalhos, apresentando-se ao serviço discretamente trajado, ao comparecimento às comemorações cívicas e às atividades extracurriculares, à manutenção do sigilo quanto aos assuntos do serviço comunicando as autoridades superiores as irregularidades que tiver conhecimento, ao atendimento com prontidão às requisições das autoridades legais. Além desses elementos comuns aos dois estatutos, o de 1975 faz referência à preservação dos princípios, ideias e fins da educação e, portanto, ao que fora determinado pelas esferas federais, amplamente reguladoras - e controladoras - das políticas dos estados (SANTA CATARINA, 1976).

O conjunto de regras previstas nos estatutos determina como o corpo docente deve agir, como vimos anteriormente, e, nos termos de Durkheim (2008), “agir bem é obedecer bem”. Desde que a regra moral se apresente, a ela se deve obediência. A disciplina moral constitui-se, portanto, como um bem em si mesma, posto que ela deve ser seguida não em razão dos atos que ordena e de suas consequências, mas porque é ordenada por autoridades reconhecidas. Toda disciplina possui um duplo objetivo: promover certa regularidade na conduta dos indivíduos e atribuir fins determinados a essa conduta. Dessa forma, a ação moral pressupõe que o membro do magistério adquira hábitos e respeite as normas estabelecidas nos estatutos, desenvolvendo capacidades fundamentais para que exista regularidade na conduta profissional e convergência entre a esfera privada (família) e a esfera pública (escola). E ainda, de acordo com os documentos, somente esta convergência poderá assegurar a manutenção do espírito de solidariedade humana e de cooperação com os pares.

\section{Sanções Disciplinares}

Para Durkheim (2008), é necessário que a ação não se dê por temor às penalidades, tampouco pelos desejos de recompensas, mas exclusivamente devido ao respeito à regra. No que concerne aos estatutos, para aqueles que não respeitam as regras prescritas e/ou não mantêm regularidade na conduta moral são previstas sanções disciplinares; única forma de evitar a anomia (ou a desordem) no interior dos sistemas de ensino. Tanto o ingressante quanto aquele que exerce o cargo deveria orientar-se de acordo com as normativas legais independentemente de gratificações e/ou de penalidades. No entanto, os dispositivos analisados fixam as ações que se realizadas pelos membros do corpo docente seriam 
dignas de punição. Enquanto no Estatuto de 1960 (SANTA CATARINA, 1960) as sanções disciplinares estavam previstas na seção intitulada “das penalidades"12, no documento de 1975 são nomeadas de "regime disciplinar"13, com uma subseção específica referente às infrações disciplinares (SANTA CATARINA, 1976).

A infração é compreendida, nesses textos legislativos, como toda ação do membro do magistério que possa comprometer a dignidade e o decoro da função pública, ferir a disciplina e a hierarquia ou causar prejuízo de qualquer natureza à administração. Os atos proibidos são assim descritos: referir-se desrespeitosamente às autoridades constituídas; deixar de comparecer ao serviço sem causa justificada ou retirar-se durante as horas de expediente sem autorização; iniciar greves, promover manifestações ou aderi-las; tratar de assuntos particulares nas horas de trabalho e/ou se valerem do cargo para desempenhar atividades estranhas as suas atribuições.

Como se pode observar, as regras previstas pelo Governo de Santa Catarina são prescrições genéricas visando conduzir a ação individual; elas serão postas em prática pelo agente moral no momento de agir. Como sublinha Durkheim (2008, p. 39), na medida em que a regra deixa-nos totalmente livres para tomar uma decisão ela deixa de se constituir um objeto de apreciação moral: “[...] o que é passível de questionamento é qual regra particular que se aplica a uma dada situação e como ela deve ser aplicada". O autor assinala ainda que sempre existe uma margem para iniciativa do agente moral, mas essa margem deve ser restrita, uma vez que o essencial da conduta deve estar previsto nas regras morais.

A força do espírito de disciplina pode ser evidenciada ainda na questão do estágio probatório, previsto no documento de 1975 (SANTA CATARINA, 1976), como requisito à confirmação ou não no cargo, ou seja, à conquista da condição de professor efetivo. São determinantes para essa avaliação: idoneidade moral, assiduidade, disciplina, eficiência e produtividade e, por último, a dedicação às atividades educacionais. Quanto aos requisitos estabelecidos para a promoção a estágios mais avançados da carreira são fixados o merecimento e o tempo de serviço. Percebe-se, assim, que a conduta em suas múltiplas dimensões permanece controlada após o ingresso no magistério.

\section{Considerações}

A expansão da escolarização primária no Estado catarinense, a partir dos anos de 1950, exigiu que a sociedade se organizasse inicialmente nos aspectos referentes à consolidação do sistema de 
ensino. À medida que o sistema vai se constituindo torna-se necessário regulamentar a carreira profissional, por meio do controle das diferentes etapas que compõem uma carreira profissional. Nesse sentido, torna-se fundamental estabelecer critérios específicos para o ingresso e a permanência no cargo, assim como sanções disciplinares. Desse modo, o papel dos estatutos foi essencial à construção não apenas de uma carreira docente, mas também à conformação de uma identidade profissional pautada em parâmetros diversos daqueles que haviam caracterizado o magistério nas décadas anteriores, quando predominava um ingresso frequentemente não ordenado pela via do concurso público e raramente pautado numa formação específica para atuar na área.

A constituição de uma identidade profissional abrange, portanto, a adesão dos indivíduos num determinado grupo. As prerrogativas legais, neste caso os estatutos analisados, constituem-se um importante instrumento de consolidação da carreira docente e, consequentemente, de uma identidade compartilhada por todos os membros do magistério público estadual. A identidade individual no momento em que adere a um corpo profissional passa a ser fortemente influenciada pela identidade do grupo. O pertencimento a um corpo profissional implica uma divisão social entre os que são efetivamente membros do magistério e os que não o são, entre os que compartilham direitos e deveres impostos pelos estatutos e os que não os compartilham, entre os que se identificam com uma determinada identidade e os que se identificam com outra, entre "aqueles que são sagrados e aqueles que são profanos" (DUBAR; TRIPIER, 1998).

Os elementos da moralidade laica estão, assim, presentes nos estatutos e foram sendo (re)definidos na relação entre as políticas educacionais e as determinações político-administrativas postas em vigência pelo Estado catarinense nas diferentes décadas observadas. O que se constatou, todavia, foi muito mais a continuidade de grande parte das prerrogativas legais que orientaram a constituição do corpo docente no início dos anos 1960 do que o estabelecimento de novas regras para o exercício do magistério nos anos 1975.

Para finalizar, é importante reconhecer que há diferenças, às vezes profundas, entre o proclamado e o executado, entre o legal e o real. As regras estabelecidas nos dois estatutos analisados orientaram de maneira geral as ações a serem realizadas pelo magistério. Evidentemente, elas “formataram" a carreira profissional e "desenharam” uma identidade para o corpo docente. A questão que fica se refere à "força" que assumiram essas regras junto ao magistério catarinense, à maneira como estes dois dispositivos legais foi recepcionada no âmbito educacional, à forma como os professores os reconheceram ou os subverteram. Colocamo-nos, para finalizar, frente a outros tantos 
objetos de investigação, suficientemente desafiadores, e que, certamente, contribuiriam para ampliar e aprofundar nossa compreensão sobre o corpo professoral de Santa Catarina.

\section{Notas}

${ }^{1}$ Pesquisa desenvolvida no quadro do Projeto de Pesquisa Educação escolar, justiça social e memória docente: as múltiplas faces das desigualdades escolares em Santa Catarina, do Laboratório de pesquisas sociológicas Pierre Bourdieu (LAPSB), da Universidade Federal de Santa Catarina (UFSC), que teve o apoio do CNPq.

${ }^{2}$ Sobre a modernização do Estado catarinense e suas reformas educacionais, ver Bombassaro e Gaspar da Silva (2011).

${ }^{3}$ Educação e sociologia (1922) foi publicada pela primeira vez no Brasil em 1928, tendo sido traduzida por Lourenço Filho. A obra A educação moral (1925) foi publicada no Brasil somente em 2008, tendo sido traduzida por Raquel Weiss.

${ }^{4}$ Solidariedade mecânica, para Durkheim, era aquela que predominava nas sociedades pré-capitalistas, onde os indivíduos se identificavam por meio da família, da religião, da tradição e dos costumes, permanecendo, em geral, independentes e autônomos em relação à divisão do trabalho social. A consciência coletiva exerce aqui todo seu poder de coerção sobre os indivíduos (COSTA, 2005).

${ }^{5}$ Solidariedade orgânica é aquela típica das sociedades capitalistas, em que, pela acelerada divisão do trabalho social, os indivíduos se tornavam interdependentes. Essa interdependência garante a união social, em lugar dos costumes, das tradições ou das relações sociais estreitas, como ocorre nas sociedades contemporâneas. Nas sociedades capitalistas, a consciência coletiva se afrouxa, ao mesmo tempo em que os indivíduos se tornam mutuamente dependentes, cada qual se especializa numa atividade e tende a desenvolver maior autonomia pessoal (COSTA, 2005).

${ }^{6}$ Considerado como um dos principais pensadores da modernidade, Émile Durkheim desenvolve a tese da divisão do trabalho social e a coloca no centro dos projetos de promoção da coesão social. A escola aparece como uma das instâncias voltadas à promoção da diferenciação social por possibilitar a cada um desenvolver plenamente seus talentos, dons e méritos.

${ }^{7}$ É sobretudo no campo da história da educação que os estudos sobre a educação brasileira mais avançaram, como vêm mostrando os múltiplos encontros nacionais e internacionais da área.

${ }^{8}$ Desenvolvido pelos economistas americanos Theodore William Schultz (1902-1998) em 1961 e Gary Stanley Becker (1930-2014) em 1964, o "capital humano" é indissociável de seu detentor, o que supõe um investimento contínuo por parte do indivíduo a fim de adquirir novos saberes e novas experiências. Tratase, assim sendo, de um estoque de recursos produtivos incorporados pelos próprios indivíduos, dependente do nível de educação, formação e experiência profissional, do estado de saúde ou dos conhecimentos do sistema econômico.

${ }^{9}$ A expressão "escolas oficiais" refere-se às escolas da rede pública de ensino e consta na Constituição do Estado de Santa Catarina de 1947, que determinava que a legislação do ensino deveria adotar os seguintes princípios: "equiparar os estabelecimentos particulares de ensino normal e primário aos oficiais do Estado" (SANTA CATARINA, 1960, Art. 176).

${ }^{10}$ Cf. Artigo $8^{\circ}$ do Estatuto do Magistério Público Estadual de Santa Catarina de 1960 (SANTA CATARINA, 1960).

${ }^{11}$ Artigos 143 e 182 dos Estatutos do Magistério Público Estadual de Santa Catarina de 1960 e 1975, respectivamente (SANTA CATARINA, 1960, 1976).

${ }^{12}$ Artigo 144 (SANTA CATARINA, 1960).

${ }^{13}$ Artigo 188 (SANTA CATARINA, 1976). 


\section{REFERÊNCIAS}

BOMBASSARO, Ticiane; GASPAR DA SILVA, Vera. Lucia. Modernização do Estado e Reformas do Ensino: manifestações da Escola Nova em Santa Catarina. In: MIGUEL, M. E. B.; VIDAL, D. G.; ARAUJO, J. C. S. Reformas Educacionais: as manifestações da Escola Nova no Brasil (1920 a 1946). Campinas: Autores Associados; Uberlândia: EdUFU, 2011.

COSTA, Maria Cristina Castilho. Sociologia: introdução à ciência da sociedade. 3. ed. São Paulo: Moderna, 2005.

DUBAR, Claude; TRIPIER, Pierre. Sociologie des professions. Paris: Armand Colin, 1998.

DURKHEIM, Émile. Educação e sociologia. Tradução de Lourenço Filho. 11. ed. São Paulo: Melhoramentos, 1978.

DURKHEIM, Émile. O ensino da moral na Escola Primária. Novos Estudos CEBRAP, São Paulo, n. 78, p. 59-75, jul. 2007.

DURKHEIM, Émile. A educação moral. Tradução de Raquel Weiss. Petrópolis, RJ: Vozes, 2008.

SANTA CATARINA. Lei n ${ }^{\circ} 2.293$, de 8 de fevereiro de 1960. Estatutos do Magistério Público Estadual de Santa Catarina. Diário Oficial de Santa Catarina, Florianópolis, 20 mar. 1960.

SANTA CATARINA. Lei n ${ }^{\circ}$ 5.205, de 28 de novembro de 1975. Estatutos do Magistério Público Estadual de Santa Catarina. Diário Oficial de Santa Catarina, Florianópolis, 23 jan. 1976.

VALLE, Ione Ribeiro. Burocratização da educação: um estudo sobre o Conselho Estadual de Educação do Estado de Santa Catarina. Florianópolis: EdUFSC, 1996.

VALLE, Ione Ribeiro. A Era da Profissionalização. Florianópolis: Cidade Futura, 2003.

VALLE, Ione Ribeiro. Carreira do magistério: uma escolha profissional deliberada? Revista Brasileira de Estudos Pedagógicos. Brasília, DF, v. 87, n. 216, p. 178-187, mai./ago. 2006.

VALLE, Ione Ribeiro; RUSCHEL, Elizete. A meritocracia na política educacional brasileira (19302000). Revista Portuguesa de Educação, Porto, v. 22, n. 1, p. 179-206, 2009. 


\section{The (re)birth of a teaching staff: the statutes for public teaching in Santa Catarina State from 1960 - 1975}

La (re)naissance d'un corp professoral: les statuts du magistère public de l'État de Santa Catarina de 1960 et 1975

\begin{abstract}
The present article analyzes one of the dimensions of the historic process of democratization of education in Santa Catarina state: the statutes regarding public teaching from 1960 and 1975, which regulated the teaching career, thus contributing to a (re)definition of the identity of teachers and to the consolidation of this profession. Among the many factors that compose the professional identity, those highlighted are the ones of moral order, considering three categories: the requirements for entering the career, the rules to remain in the teaching profession and the disciplinary sanctions. The documents, by establishing competencies and conducts that must be followed by all teachers, established a moral order and inaugurate regulations for the teaching profession. We find a continuity of most of the legal prerogatives that guided the constitution of teaching staff in the early 1960s and the establishment of new rules for the exercise of teaching in the 1970s. We also find that the two mechanisms present a normative character that is strongly based on moral guidelines, which leads us to seek Émile Durkheim's writing (1858-1917) related to the disciplinary element of morality.
\end{abstract}

Keywords: Statutes of Teaching. Professional Identity. Moral Order.

Ione Ribeiro Valle

E-mail: ione.valle@ufsc.br

Danielly Samara Besen

E-mail: daniellysamara@hotmail.com

Silvana Rodrigues de Souza Sato

E-mail:sil.sato@uol.com.br

\section{Résumé}

Cet article analyse une des dimensions du processus historique de démocratisation de l'éducation de l'État de Santa Catarina, à savoir: les statuts du magistère public des années 1960 et 1975 qui ont réglementé la carrière du magistère, en contribuant ainsi à une (re)définition de l'identité des enseignants et à la consolidation de la profession enseignante. Parmi les aspects qui composent l'identité professionnelle, on a pu mettre en relief l'ordre moral, en considérant trois catégories : les requis à l'accès à la carrière, les règles de permanence dans le magistère et les sanctions disciplinaires. Les documents, qui instituent les compétences et les conduites à être suivies par tous, établissent un ordre morale et inaugurent un ordre professoral. Nous avons observé la continuité d'une grande partie des prescriptions légales qui ont orienté la constitution du corp enseignant dès les année 1960 et ont établi de nouvelles régles à l'exercice du magistère dans les années 1975. Nous avons aussi vérifié que les deux dispositifs présentent un caractère normatif fondé sur des règles morales, ce qui nous a amené à chercher des écrits d'Émile Durkheim (1858-1917) relatifs à l'élément disciplinaire de la moralité.

Mots-clés: Statuts du Magistère. Identité Professionnelle. Ordre Morale.

Enviado em: 7/6/2014

Aprovado em: 21/7/2015 